\title{
Employee Satisfaction and Related Factors among Public Healthcare Workers in Sri Lanka: A Case Study on Regional Directorate of Hambanthota
}

\author{
Sanjeewa Chamal GG ${ }^{1 *}$ and Herath Dilina ${ }^{2}$ \\ 1Medical Administrator-Ministry of Health, Sri Lanka \\ ${ }^{2}$ PhD. Senior Lecturer, School of Management., ESOFT, Sri Lanka
}

*Corresponding author: Dr. GG Chamal Sanjeewa, Research fellow, Ministry of Health-Sri Lanka, Tel: 07723737 66; Email: chamalsanjeewa@gmail.com

\section{Research Article}

Volume 2 Issue 1

Received Date: July 02, 2018

Published Date: August 17, 2018

\section{Abstract}

The present study describes the level of job satisfaction and its selected correlates of Public Health Officers -PHO who are working in District of hambantota. Three hundred and twenty six (326) Public Health Officers who are working in district of Hambantota are included in the study as a convenient sample. Job satisfaction was assessed with thirty questions under the ten sub headings which were developed based on two factor theory of Harzburg et al.

A majority 153 (59.5\%) of the public Health Officers-PHO had scored their level of job satisfaction as neither satisfied nor dissatisfied and $65(23.7 \%)$ are satisfied. However $39(15.2 \%)$ of the study population are not satisfied while $1.6 \%$ are strongly satisfied and none of them are strongly dissatisfied. A majority $226(88 \%)$ of the PHO are satisfied on support exerted at MOH level. More than half of the PHO are not satisfied on existing appraisal system, promotion based on work performance, extra payment and salary increment within the system.

This study first of the nature in Sri Lanka and data are not available for comparison. Comparison between studies in local or international literature is difficult and inappropriate unless the workings seek. Study shows that motivational factors affect more than hygienic factors to the employee. Experience as a PHO, presence of immediate supervisor, age of the PHO and number of children $n$ has significant influence on job satisfaction while total population, mode of travelling, place of residence, and distance from place of residence to the field has no significant influence on job satisfaction. Improving basic facilities in working environment, appointing PHNS of SOHM for each MOH area, provision of efficient feed back at $\mathrm{MOH}$ level, conducting regular in service programmes to update the knowledge are the main recommendations.

Keywords: Health work force; Employee satisfaction; Two factor theory of Harzburg

\section{Introduction}

Job satisfaction among public sector employees within Sri Lanka, specifically the health environment is becoming an area of major concern as highlighted by recent research studies and media reports. An exodus of professional staff and a lack of resources have exacerbated the current problem impeding on effective 
and efficient service delivery. Literature validates that factors such as poor working conditions, staff shortages, below competitive salaries, a lack of promotional opportunities are some of the major factors contributing to employee dissatisfaction within the sector [1-3].

Health care is defined as a 'multitude of services rendered to individuals, families, and community by agents of the health services or professions for the purpose of promoting, maintaining, monitoring, and restoring health [4].

Job satisfaction is a frequent studies subject in work and organizational literature. This is mainly due to the fact that many experts believed that job satisfaction trends can affect labour market behaviour and influence work productivity, work effort, employee's absenteeism and staff turnover. More over job satisfaction is considered a strong predictor of overall individual well being [5] as well as a good predictor of insertion or decision of employees to leave a job [6].

It has been shown that low job satisfaction is a major cause of turnover among health care providers [7]. It affects the quality of service and organizational commitment [8] and may be associated with staff shortages [9] or psychosocial stress. In the health care sector, only few organizations have made job satisfaction survey as a top priority. Also job satisfaction is important in everyday life. Organizations have significant effect on the people who work for them and some of the effects are reflected in how people feel about their work. These make job satisfaction an issue of substantial importance for both employers and employees, as they are more like to profit from lower staff turnover and higher productivity if their employees express a high level of job satisfaction.

Perhaps this is because; they have failed to understand the significant opportunity that lies in front of them. Satisfied employees tend to be more creative and committed to their organizations. Recent studies have shown a direct correlation between staff satisfaction an and patient satisfaction [10].

Hospital administrators who can create work environments that attract, motivate and retain hardworking individuals will be better positioned to succeed in a competitive health care environment demanding quality and cost-efficiency. What's more, they may even discover that by creating a positive workplace for their employees, they've increased their own job satisfaction as well. The premise of this research is focused on ascertaining how variables such as the work environment, pay, supervision, co-workers and promotion impacts on job satisfaction of civil servants at an institution residing under the Department of
Health. According to Luthans (1989), high or low employee turnover rates, absenteeism and grievances lodged are factors that indicate whether job satisfaction or job dissatisfaction exists within organizations.

Previously highlights some of the major problems experienced within the Department being:

- Employee turnover rates;

- Major reasons why employees are leaving the department;

- Costs incurred due to sick leave taken;

- Types of misconduct addressed at disciplinary hearings and

- Grievances and disputes lodged.

- So it's vital to carry out this type of research.

Unlike productivity, absenteeism and turnover, job satisfaction is present only inside an individual's mind and cannot be measured directly. Methods for indirectly measuring job satisfaction include observing employees, interviewing them and asking them to complete a questionnaire. Many organizations and researchers favour questionnaires because personal observations interviews are very time consuming. Job satisfaction can be measured using either single-item, general or facet measures.

According to Heller and Hindle (1998), Herzberg's two factors is a set of motivators that drives people to achieve. Nagy (n.d.) asserts that Herzberg's theory consists of two dimensions known as "hygiene" factors and "motivator" factors. According to Herzberg (1959) cited in Ruthankoon and Ogunlana (2002), the hygiene factors also known as extrinsic factors are the parts of the jobs which create dissatisfaction but, if not present, only return the worker to a neutral point of job satisfaction.

These job factors include supervision, interpersonal relations, benefits, job security, salary and working conditions. Herzberg states that hygiene issues cannot motivate employees but can minimize dissatisfaction and serve as a point of departure for motivation. On the other hand, satisfying motivator needs which are related to job tasks, job content and intrinsic aspects of the job can lead to job satisfaction, but the absence thereof cannot lead to job dissatisfaction. According to Robbins, et al. (2003), investigations conducted by Herzberg in terms of the intrinsic (motivators) factors and extrinsic factors (hygiene) suggest that the opposite of satisfaction is not dissatisfaction as was traditionally believed. The results of the studies reflected that the opposite of satisfaction is no satisfaction (motivators) and the opposite of dissatisfaction is no dissatisfaction (hygiene factors). 


\section{Epidemiology international journal}

According to Schermerhorn (2003), Herzberg's twofactor theory is an important frame of reference for managers who want to gain an understanding of job satisfaction and related job performance issues. Schemerhorn asserts that Herzberg's two-factor theory is a useful reminder that there are two important aspects of all jobs: what people do in terms of job tasks (job content), and the work setting in which they do it (job context).

Schermerhorn suggests that managers should attempt to always eliminate poor hygiene sources of job dissatisfaction in the workplace and ensure building satisfier factors into job content to maximise opportunities for job satisfaction.

In this theory authors stated that job factors could be classified according to whether the factors contribute primarily to satisfaction or to dissatisfaction. Two aspect of the theory are unique and account for the attention it has received. Firstly two-factor theory says that satisfaction and dissatisfaction do not exist on a continuum running from satisfaction through natural to dissatisfaction (Figure 1).

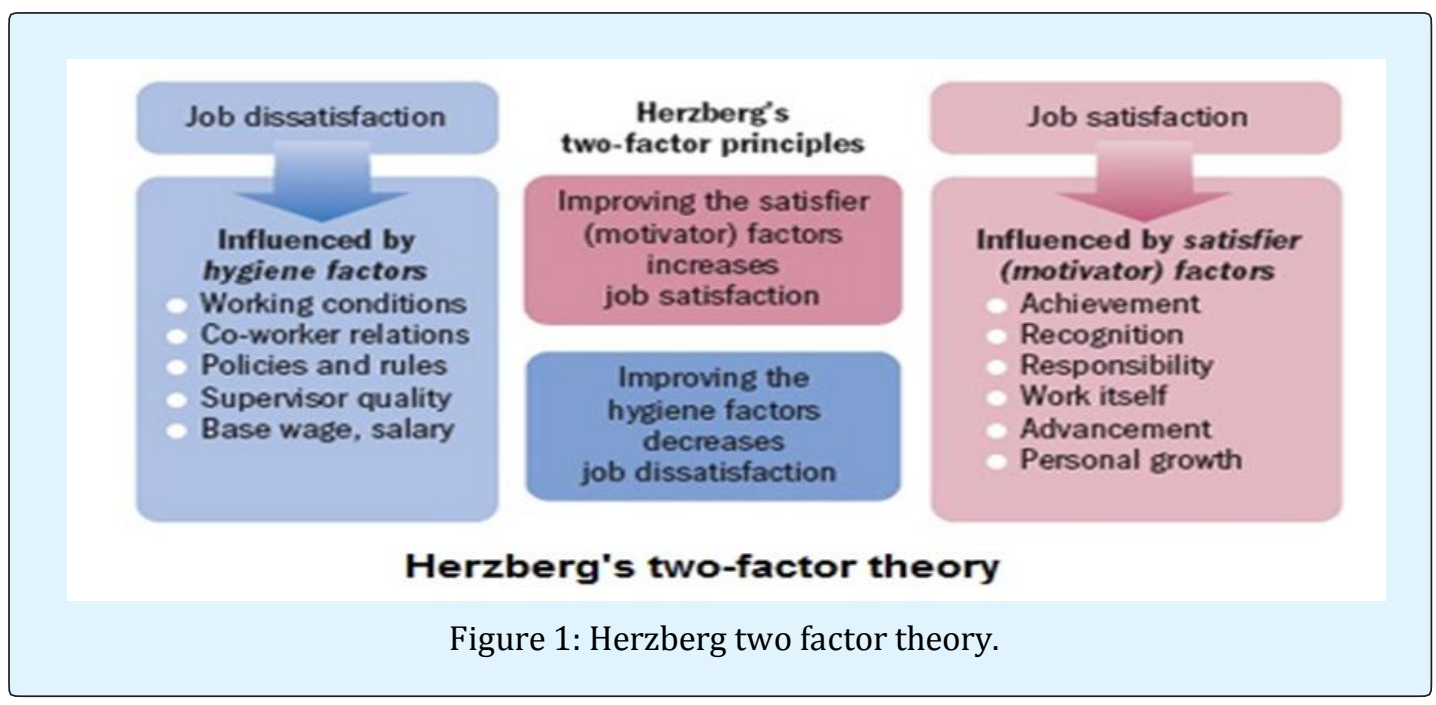

An organization's polices can be a great source of frustration for employees if the polices are unclear or unnecessary $r$ if not everyone is required to follow them. Although employees wills never feel a great sense of motivation or satisfaction due to company policies, it can decrease dissatisfaction in this area by marking sure your policies are fair and apply equally to all. Also, when printed copies of programme policies-and procedures manual easily accessible among all members of the staff and they will be more satisfied. It states that it is important to have a written manual and if you do not have a written manual, create one, soliciting staff input along the way. If already available consider updating it again, with staff input.

Quality supervision is a prerequisite for effective worker practice. A good supervisor promotes familycentered philosophy, empowers, balances direction with need for worker autonomy, is available, serves as an ally and advocates foe saff, acknowledge effective job performance, prevents workers' accumulation of large amounts of overtime, and helps set priorities. Inadequate supervision contributes to worker dissatisfaction which then may lead to turnover. When supervision os perceived as inadequate or not supportive, workers may be more likely to be dissatisfied.
In situations where workers did not feel supported by their supervisions, other potentially negative working conditions became more significant. On the other hand, supervisory support was found to be a critical factor in mediating the stress and frustrations of their job and motivating caseworkers stay.

\section{Formulation of Research Objectives and Research Questions}

\section{Main Objective}

To explore the level of job satisfaction in relation to hygienic and motivation factors and its correlates among Public Health Officers.

\section{Specific Objective}

- To assess how hygienic and motivation factors affect job satisfaction

- To make recommendations to improve the job satisfaction among Public Health Officers.

\section{Research questions}

A-How hygienic factors affect to job satisfaction?

B- How motivation factors affect to job satisfaction? 


\section{Analytical Framework}

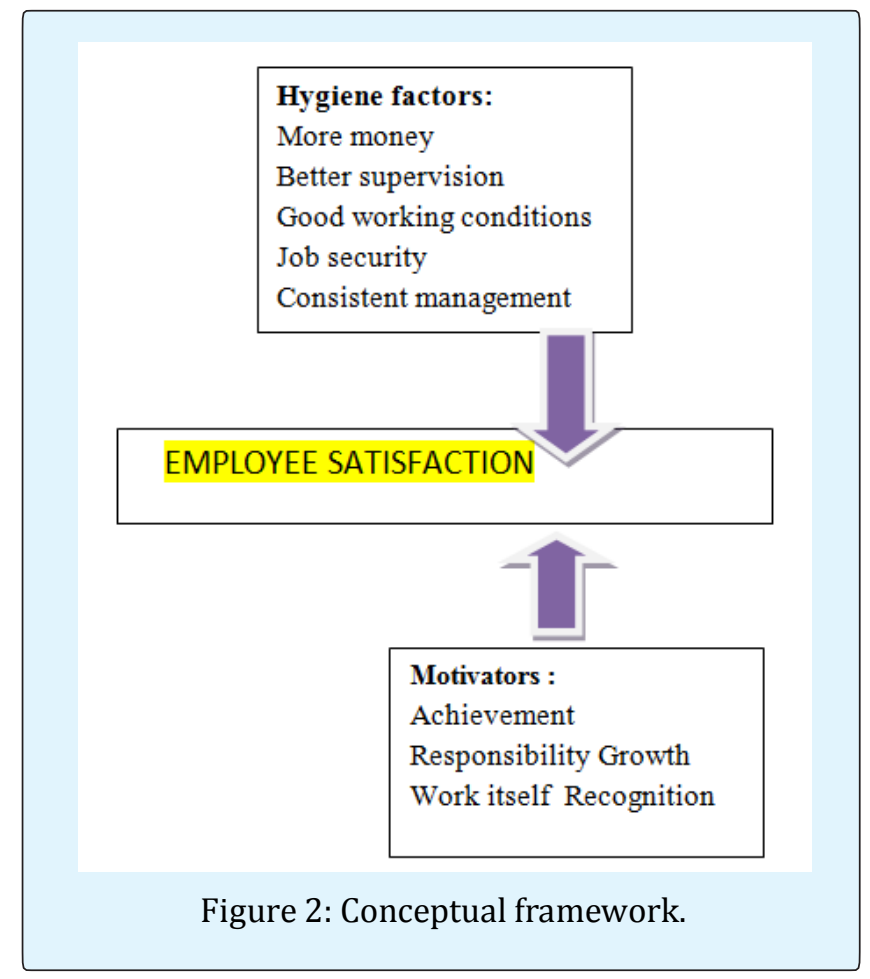

\section{Methods}

By applying Research Onion

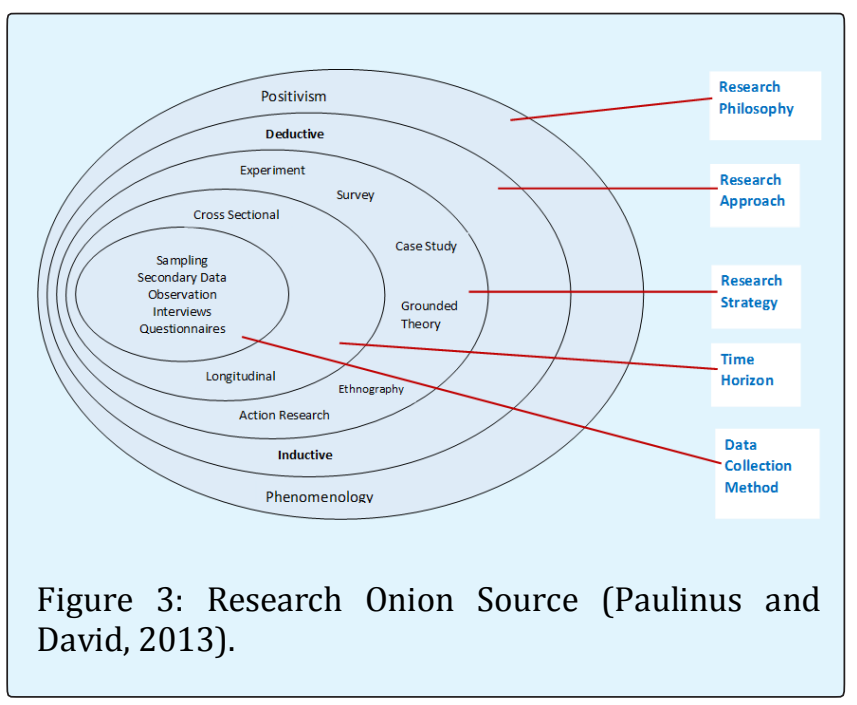

Philosophy of the study: The study conducted with positivism approach as the philosophy due to limited time period. The research problem would be observed under quantitative data collection.

Research Approach: The Deductive approach used considering the availability of time through existing theories.
Research Strategy: A case element strategy would be used

Time Horizon: Due to time constraints, the cross sectional time horizon would be used during September 2017 to October 2017 period.

Research Method: Quantitative methods used. A community based descriptive cross sectional study.

Research Tools: As the research tool, specific self administrated questionnaires would used..

Population and Sample Size: All the PHO who are working in the health administrative district of Hambantota will be selected as the study population. This includes 326 PHO who employed. All the Health Officers who fulfilled the inclusion criteria considered as the study sample. So this is a census. Therefore a sampling technique was not applicable.

\section{Eligibility Criteria}

Eligibility criteria used depend on their administrative structure and their field experience.

Data Collection Method: Primary data would be collected. Primary data collected through Self administered questionnaire and results of the questionnaires used for quantitative data analysis. (Annexure 1-Questionnaire).

\section{Instrument Development}

Following a systematic review of the international literature pertinent to the subject in question, studies reporting on multidimensional job satisfaction instruments were collected on the basis of theoretical models that integrate the finding of empirical research related to satisfaction and motivation. The most common approach to measuring job satisfaction involves the use of questionnaires.

Data were collection primarily by the principal investigator himself. Data collection was carried out the monthly conference day as it is mandatory to all the Public health officers to attend monthly meetings at District office Hambantota. Those who are absent on the monthly conference day questionnaire was administered on next salary day.

\section{Ethical Consideration}

The research topic itself is ethical. The researcher would maintain the research at highly ethical level throughout the study. The researcher would not use his position or power to collect data by doing something harmful to someone else to get the data forcefully. During the research, would be specifically excluding the respondents as the minors, elderly and mentally unbalanced people. 


\section{Analysis of Data}

Serial numbers were given to questionnaire at the stage of data entry. Data were coded and computer analysis was performed using Statistical Package for Social Science (SPSS) by principle investigator. Frequency and Chi square test was applied where appropriate to assess the significance of relationship. A probability of $<0.05$ was considered as significant.

\section{Results}

\begin{tabular}{|c|c|c|}
\hline $\begin{array}{c}\text { Level of } \\
\text { satisfaction }\end{array}$ & Frequency (N) & Percentage \\
\hline Strongly satisfied & 4 & 1.6 \\
\hline Satisfied & 61 & 23.7 \\
\hline Neither satisfied & 153 & 59.5 \\
\hline Nor dissatisfied & & 15.2 \\
\hline Dissatisfied & 39 & 0 \\
\hline $\begin{array}{c}\text { Strongly } \\
\text { dissatisfied }\end{array}$ & 0 & $\mathbf{1 0 0 . 0 0}$ \\
\hline Total & $\mathbf{2 5 7}$ & \\
\hline
\end{tabular}

Table1: Frequency distribution of Public Health Officers according to final level of satisfaction.

According to the final score of satisfaction, more than half of the study population 153 (59.5\%) is neither satisfied nor dissatisfied. Nearly one fourth of the study population 65 (25.3\%) was satisfied (Strongly satisfied) with their job, while 39 (15.2\%) of them were dissatisfied. None of them rated the level of job satisfaction as strongly dissatisfying.

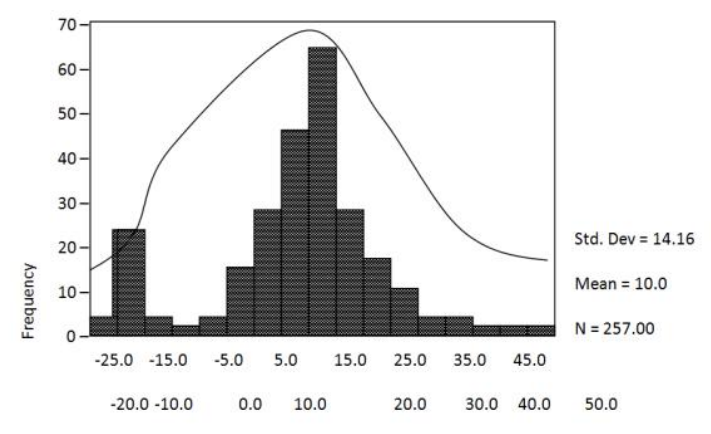

Figure 1: Histogram and binomial distribution of total job satisfaction with final score total score for job satisfaction.

\section{Total Score for Job Satisfaction}

Distribution of total score of job satisfaction follows a more or less normal distribution, but from -20 to 5 , there is some deviation from the normal distribution. SD is 14.15 and mean is 10.2. Final score of every questionnaire was taken by subtraction total minus count from total positive count; then final score was categorized in to following five group as shown below.

\begin{tabular}{|c|c|c|}
\hline $\begin{array}{c}\text { Total job } \\
\text { satisfaction }\end{array}$ & Frequency (N) & Percentage (\%) \\
\hline Strongly satisfied & 7 & 2.7 \\
\hline Satisfied & 106 & 41.2 \\
\hline Neither satisfied & 133 & 51.8 \\
\hline Nor dissatisfied & 11 & 4.3 \\
\hline Dissatisfied & 0 & 0 \\
\hline $\begin{array}{c}\text { Strongly } \\
\text { dissatisfied }\end{array}$ & $\mathbf{2 5 7}$ & $\mathbf{1 0 0 . 0 0}$ \\
\hline Total & & \\
\hline
\end{tabular}

Table 2: Frequency distribution of Health Officers according to responses to variables represent the motivator (satisfactory) issues.

One hundred thirty three (51.8\%) of study population has expressed that they are neither satisfied nor dissatisfied with variables which reflect motivator (satisfactory) issues and 113(43.9\%) are satisfied with factors which reflect the motivator issues.

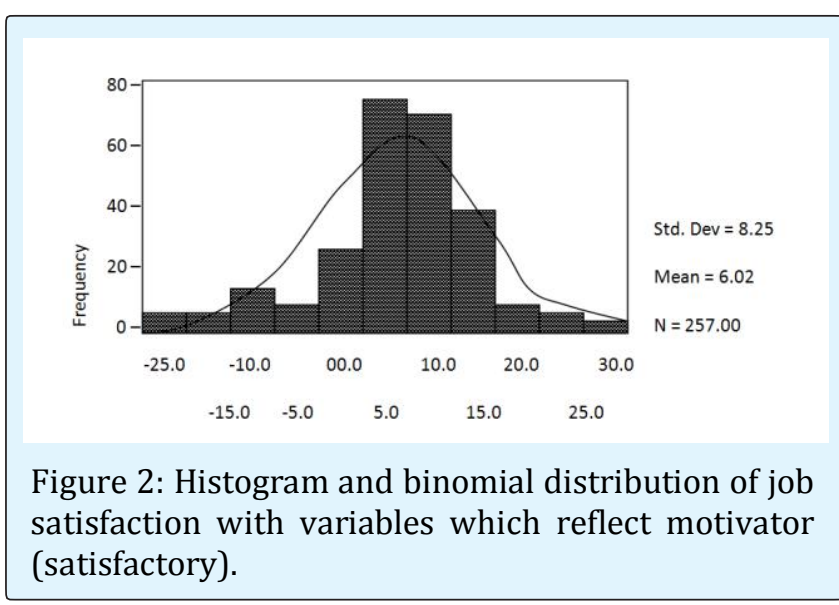

\section{Distribution of Score from Satisfactory Variables}

Total score from satisfactory variables distribution of total score from motivator (satisfactory) is fallowing a more or less like normal distribution but - 5 to 5 has little deviation from normal distribution. SD is 8.25 and means 6.2.

\begin{tabular}{|c|c|c|}
\hline Scale & Frequency (N) & Percentage (\%) \\
\hline Strongly satisfied & 4 & 1.6 \\
\hline Satisfied & 60 & 23.3 \\
\hline Neither satisfied & 176 & 68.5 \\
\hline nor dissatisfied & & \\
\hline Dissatisfied & 17 & 6.6 \\
\hline $\begin{array}{c}\text { Strongly } \\
\text { dissatisfied }\end{array}$ & 0 & 0 \\
\hline Total & $\mathbf{2 5 7}$ & $\mathbf{1 0 0 . 0 0}$ \\
\hline
\end{tabular}

Table 3: Frequency distribution of Public Health Midwives according to responses to variables which represent the dissatisfactory issues. 


\section{Epidemiology international journal}

One hundred and seventy six (68.5\%) of the study population has expressed that they are neither satisfied nor dissatisfied with variables which represent the satisfactory side and $64(24.9 \%)$ were satisfied with factors relating to satisfaction.

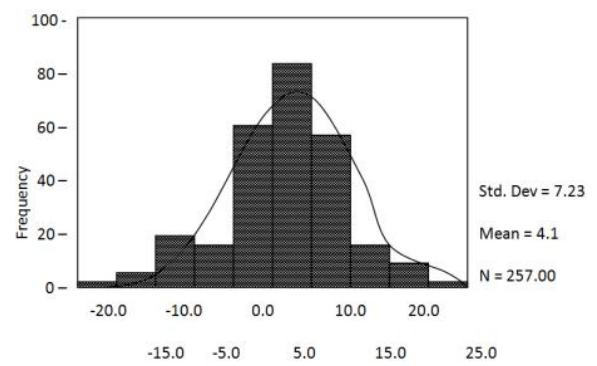

Figure 3: Distribution of score from dissatisfactory variables.

Distribution of final score from hygienic issues (dissatisfactory variables) are following a more less normal distribution but -5 to 0 have some deviation from the normal distribution. SD is 7.23 and mean is 4.1.

\begin{tabular}{|c|c|c|}
\hline Variable & Mean & SD \\
\hline $\begin{array}{c}1 . \quad \text { Motivation Factors (Mean of } \\
\text { Achievement (5.01) Responsibility (6.23) } \\
\text { Growth, (6.35) } \\
\text { Work itself) }\end{array}$ & 6.02 & 8.25 \\
\hline $\begin{array}{l}\text { 2. } \\
\text { Hygiene Factors (Mean of } \\
\text { Money, (5.10) } \\
\text { Supervision (4.25) } \\
\text { Good working (5.37) condition, } \\
\text { Job security (4.59) } \\
\text { Consistent management (3.12) }\end{array}$ & 4.10 & 7.23 \\
\hline
\end{tabular}

Table 4: Summary of Factors Affection Job Satisfaction.

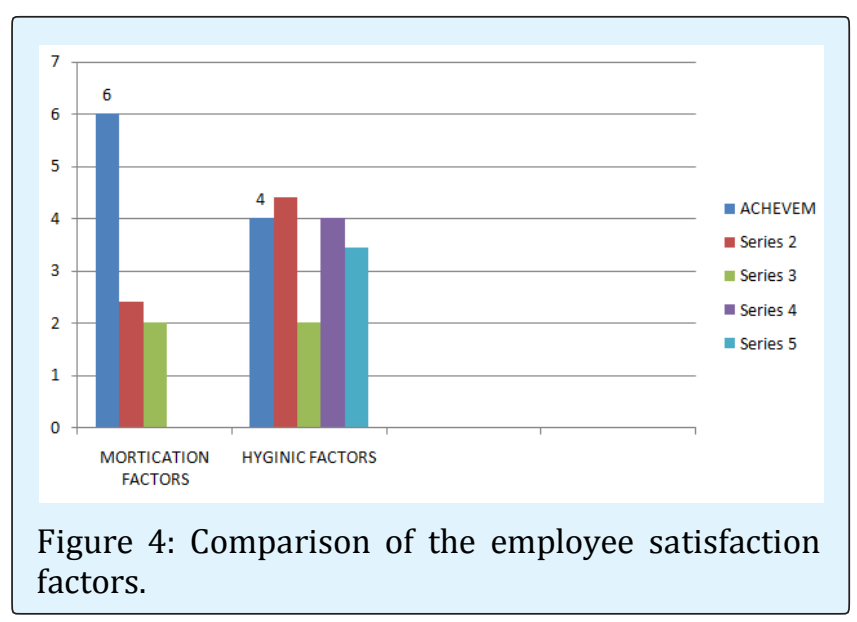

According to this comparison motivation affect more than hygienic factors. Among motivation factors responsibility has high mean value and among hygiene factors good working condition has high mean value.

\section{Final Job Satisfaction}

Appointing at least PHNS or SPHM for each $\mathrm{MOOH}$ area or re distributing existing available carder as it is expected to have at least one supervising for each $\mathrm{MOH}$ area, as availability of immediate supervisor has significant influence on the level of job satisfaction. Provision of effective feed back at $\mathrm{MOH}$ level to improve work performance. Improve the works appraisal system, scheme of promotions based on performance and also financial benefits as more than half of the study population were not satisfied with existing systems and this enhance the level of job satisfaction of the PHMM.

The central objective of this study was to establish the impact of variables, such as the work itself, pay, supervision, promotion and relationships with coworkers on employees in terms of job satisfaction at a public sector institution in the Western Cape. A literature survey was conducted to form the theoretical premise for the study. Factors such as pay, the work itself, supervision, relationships with co-workers and opportunities for promotions have been found to contribute to job satisfaction.

The empirical findings from the study indicate that employees at the public health institution in the Western Cape, where the research was conducted, are most satisfied with their co-workers, followed by the nature of the work itself and the supervision they receive. They however, indicated that they are less satisfied with promotional opportunities and least satisfied with the pay they receive. The study revealed that $153(59.5 \%)$ of study population is neither satisfied nor dissatisfied with their job and $65(25.3 \%)$ of them rated their level of job satisfaction as satisfied (both strongly satisfied and satisfied), while 39 (15.2\%) were dissatisfied. None of has rated as strongly dissatisfied while $(1.6 \%)$ of them has rated as strongly satisfied.

Final score job satisfied had a medical of 12 (mean 10.245) while the medical for the motivators (satisfiers) and the hygienic (dissatisfied) were at 7 (mean 6.214) and 4 (mean 4.05) respectively. Therefore the final score had been more influenced by the variables which represent motivator (satisfiers) variables than hygienic or (dissatisfiers) variables. Eighty seven (33.9\%) of the PHO working in Hambantota district had total field experiences as PHO for 16 to 20 years and majority 25 (9.7\%) of PHO had worked as PHM for 4 years in the present station. Both minimum and maximum experience in station and total field experience as PHO were 1 (one) and 26 (twenty six) years, with a mean of 9.632 respectively.

Only $66(25.7 \%)$ of the PHO are living in their quarters while majority 159 (61.8\%) are living in their own home. Fifty six (21.8\%) of the PHO were using 
moped as a mode of traveling, while 170 (66.1\%) travelled by foot although there was no significant difference observed with the level of job satisfaction. .Only 88 (34.2\%), 63 (24.5\%) of PHO had either PHO or SPO as their immediate supervisors respectively while $76(29.6 \%)$ had both of them. However 30 (11.7\%) of PHO do not have any of supervisors and this has statistically significant on the level of job satisfaction. Majority of the PHM are not satisfied with existing extra payment, salary increment, work load and facilities provided by the government, while they are satisfied with the support extended by $\mathrm{MOH}$ to solve the field problems.

More than half of the Public Health Officers working in Hambantota district, were not satisfied with the appraisal system within the institution and promotional scheme based on the work performance in comparison to private sector. The results of the study should be interpreted with caution due to the limitations of the study. Cognizance must also be taken of the fact that the results obtained from the research may be specific to the directorates where the investigation was conducted. This can be attributed to the fact that a non-probability sample in the form of convenience sampling was utilised in the study. Hence, the results acquired cannot be generalised with confidence to other public institutions .Another contributing factor impacting on generalisability is the fact that only the public health personnel were targeted in the study.

Therefore, the results of the study cannot be inferred to other occupational classes of a similar category resulting in the external validity of the study being compromised. In addition, although the response rate for the current study is adequate, the composition of the sample could have introduced elements of bias in the research findings. Final job satisfaction had a median of 12 (mean 10.245, while the median for the Motivator (satisfactory) variables and the hygienic (dissatisfactory) variable were at 7 (mean 6.214) and 4 (mean 4.05) respectively. This difference demonstrates that the total satisfaction score is more influenced by the Motivator (satisfactory) variables than the hygienic (dissatisfactory) variables.

\section{Recommendations and Conclusion}

When it comes to mobilizing staff, success is mainly based on ability to work with emotions. This means that you need to create an environment that is adapted to the development of positive emotions. Fostering professional and especially personal growth plays a major role in creating favorable sentiments towards organisation for employees. People who are encouraged to grow and develop are more likely to produce more efforts, push beyond their boundaries and deliver value in any task they undertake.

Provide Training Opportunities is important. Personal accomplishment is at the top of Maslow's pyramidal hierarchy of needs. That's why it's not surprising many of us develop a thirst for continuous learning and development. When you offer training opportunities, you give your employees the chance to deepen their knowledge and get specialised in a field they enjoy. As a matter of fact, training program are a win-win solution for employees and employers alike. And don't worry, bettering their skills will not increase their likeliness to fly away. It's actually an investment (and not an expense) your make for your employees which encourages them to stick around. Who wouldn't want to know that they are worth investing in them? Whether employees seek internal or external training, you should allocate them some time to spend specifically on their self-development.

- Organise a celebration or go out for lunch

- Plan a post-work drink with all the members of your organisation

- Write a personalised thank-you note

The best place where they belong will be organization that shares common values and interest. In order to motivate them, it is important to know what they are looking from life and where organizational goals can be the same as theirs, giving them a chance to pursuit their own ideology. The impact of intrinsic motivation has a very strong impact on their performance. Some employee are mostly intrinsically motivated and individual attention from top management is highly powerful. They want to bring more in success of the company simply because they like to be here. If loyalists have a problem Increasing employee satisfaction and motivation with his or her current job position, it is better to assign him or her to another department or project where he or she has more expertise and skills. These people creating a strong chain in collective and losing them may cause very harmful problems.

To motivate an employee to perform certain activity, it is necessary to reward his or her achievement corresponding to his or her own appreciation that should be linked to the organization's goals. Management should carefully formulate realistic level of expected performance for its subordinates and inspire them that they are able to achieve a desired goal only if they exert their force. The degree on how employees rate their strength depends on the management expectations. If the level of the expectation is high, the performance of subordinates is also probable to be intense. Otherwise if the level of expectations stands low, then the performance is expected to be low. If the 


\section{Epidemiology international journal}

expectations not exist, then the obstacles for achieving the goal generate a sense of futility.

The more value of non achieved goal, the greater the sense of futility by following reduction of goal level, and if the goals are not realized several times, then the downturn of assessment of its reality and motivation will be lowered. Sense of futility reduces the motivation and as a result low motivation will mark down performing contribution to the goals.

It should be noticed that employees are able to achieve the desired degree of performance required only if that delegated powers and personal inputs are sufficient for the task accomplishment. The decisions you take can have a dual impact on employee satisfaction. Either positive or negative. Improving job satisfaction is a work of endurance that requires the collaboration and involvements of all. Job satisfaction brings motivation and triggers engagement, turning your employees into your organization's best allies.

\section{References}

1. Adams JS (1965) Inequity in social exchange. Advances in experimental psychology, ed. Berkowitz, Academic Press, New York, 2: 267-299.

2. Agho AE, Muller CW, Price JL (1993) Determinants of employee job satisfaction. An empirical test of a causal model. Human Relation 46(8): 1007-1028.

3. Bowen CF, Radhakrishna R, Keyser R (1994) Job satisfaction and commitment of 4-H'. Journal of Extension 32(1).
4. Cabrita J, Perista H (2006) Measuring job satisfaction in surveys - Comparative analytical report EU Countries. European Foundation for improvement of living and working condition.

5. Herzburg FI, Mausner B, Peterson RO, Capwell DR (1957) Jobttitude: Review of research and Opinion Pittsburg, PA Psychological service of Pittsbugh.

6. Herzberg F, Mausner B, New Orleans LA, Snyderman BB (1959) The motivation to work $2^{\text {nd }}$ (Edn.), New York: John Wiley \& Sons.

7. Silver PT, Pouin JE, Mannin RC (1997) Surviving the bureaucracy: The predictors of job satisfaction for the public agency supervisor. The Clinic Supervisor 15(1): 1-20.

8. Stephen PR (1995) Organizational behaviors, $6^{\text {th }}$ (Edn.), Prentice-Hall international (UK) Limited, London, pp: 184-188.

9. Taylor FW (1911) The principles of Scientific Management: The Special House Committee, Harper \& Row, Boston.

10. Uragoda CG (1987) A History of Medicine in Sri Lanka - from earliest time to 1948, Sri Lanka Medical Association, Colombo, pp: 326.

11. Van de Looij F, Benders J (2005) Not just money: Quality of working life as employment strategy. Health Manpower Management 21(3): 27-33. 